I MAGES DX

\title{
Drumstick Digits: A Case of Clubbing of the Fingers and Toes
}

Kim Nguyen, mD

Paul Aronowitz, MD, FACP
Department of Internal Medicine, California Pacific Medical Center, San Francisco, California.

Disclosure: Nothing to report.
A 42-year-old man with chronic kidney disease and a history of childhood repair of Tetralogy of Fallot was admitted with pneumonia. Examination of his extremities revealed clubbing of his fingers (Figure 1) and toes (Figure 2).

Clubbing may be primary, known as pachydermoperiostosis, or secondary, due to a variety of neoplastic, pulmonary, cardiac, gastrointestinal, and infectious diseases. ${ }^{1}$ Examination reveals softening of the nail bed with loss of the normal angle between the nail and the proximal nail fold, an increase in the nail fold convexity, and thickening of the distal phalange with eventual hyperextensibility of the distal interphalangeal joint. Diagnosis is based on various criteria,

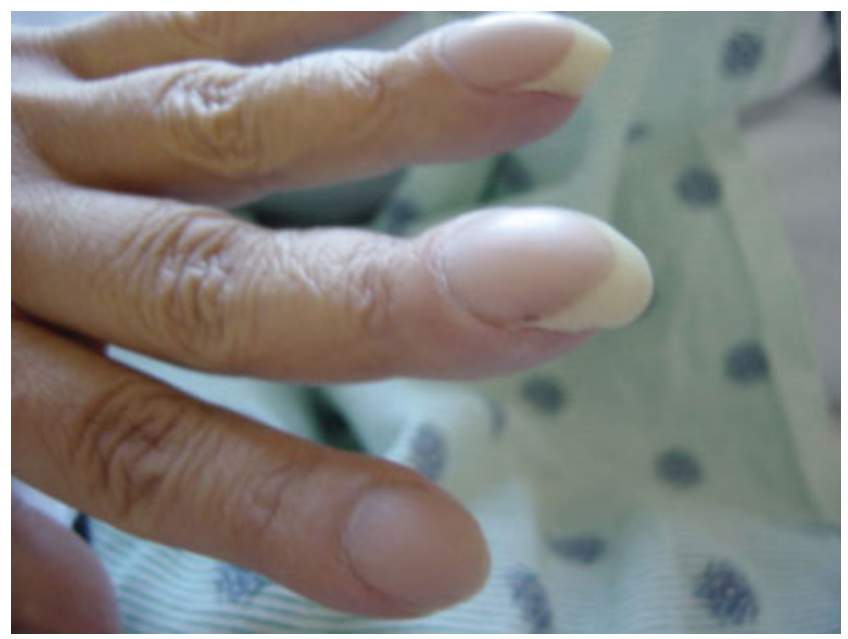

FIGURE 1. "Drumstick fingers" or clubbed fingers.

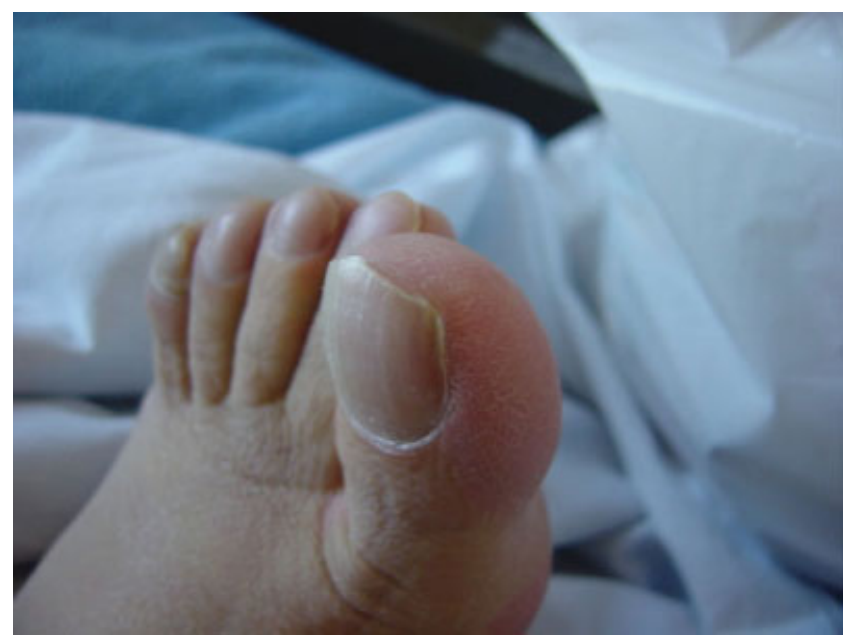

FIGURE 2. Clubbing of the toes.

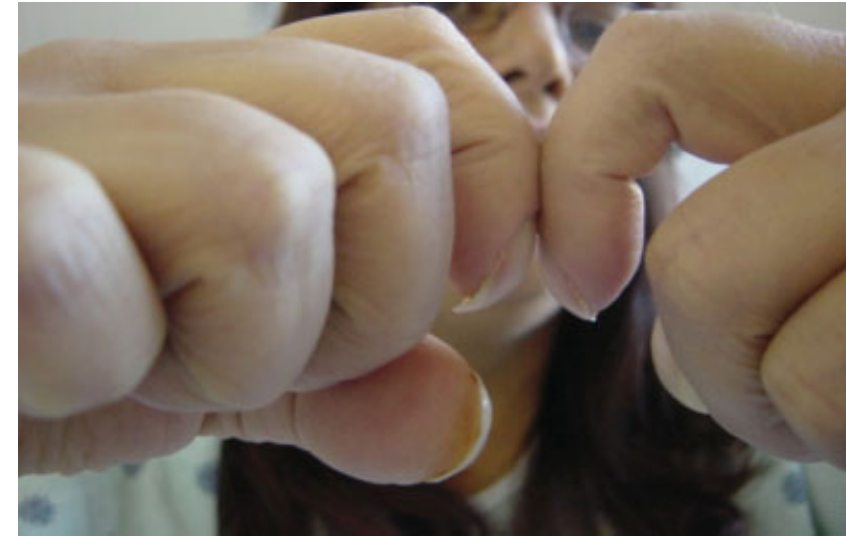

FIGURE 3. Schamroth's sign.

such as the profile angle (Lovibond's angle) or distal phalangeal to interphalangeal depth ratio. The loss of the normal diamond-shaped window created by placing the back surfaces of terminal phalanges of similar fingers together, also known as Schamroth's sign, was noted by Dr. Leo Schamroth when he developed endocarditis and is one of the few eponyms named after both a physician and the patient in whom it was found (Figure 3). ${ }^{2}$ Recent literature suggests that vascular endothelial growth factor (VEGF), a plateletderived factor induced by hypoxia, may play a role in digital clubbing. ${ }^{3}$ Processes that alter normal pulmonary circulation disrupt fragmentation of megakaryocytes in the lung into platelets. Consequently, whole megakaryocytes enter the systemic circulation and become impacted in the peripheral capillaries, where they cause stromal hypoxia and release of platelet-derived growth factor and VEGF, leading to the vascular hyperplasia that underlies clubbing.

\section{Address for correspondence and reprint requests:}

Kim Nguyen, MD, California Pacific Medical Center, Internal Medicine, 2333 Buchanan, San Francisco, CA 94115; Telephone: 800-743-7707; Fax: 415-775-7437; E-mail:

ktnguyen@post.harvard.edu Received 20 July 2009; revision received 14 September 2009; accepted 20 September 2009.

\section{References}

1. Spicknall KE, Zirwas MJ, English JC. Clubbing: an update on diagnosis, differential diagnosis, pathophysiology, and clinical relevance. J Am Acad Dermatol. 2005;52:1020-1028.

2. Cheng TO. A unique eponymous sign of finger clubbing (Schamroth sign) that is named not only after a physician who described it but also after the patient who happened to be the physician himself. Am J Cardiol. 2005;96:1614-1615.

3. Martinez-Lavin M. Exploring the cause of the most ancient clinical sign of medicine: finger clubbing. Semin Arthritis Rheum. 2007;36:380-385. 